\title{
Pedagogia Medieval Ocidental: corpo e educação em Tomás de Aquino
}

\section{Resumo}

A unidade matéria-espírito na antroplogia medieval encontra seu lugar apropriado quando Tomás de Aquino assume a postura de Aristóteles de radical aceitação da realidade concreta e, no homem, a intrínseca união de alma e matéria. Alma e corpo agem juntos e unificadamente em tudo o que é humano. E a realidade material deixa de ser vista como mera alegoria. A afirmação "Anima forma corporis" está na própria essência da liturgia e em muitos aspectos da educação, que sem o reconhecimento dessa "in-formação", tornarse-iam ininteligíveis, pois, no fundo, não são compatíveis com o exagerado dualismo, que estabelece alma e corpo como realidades estanques. Embora geralmente negassem teoricamente o "Anima forma corporis", muitas práticas dos educadores medievais estão baseadas nesse princípio.

Palavras-Chave: Alma e corpo. Tomás de Aquino. Liturgia. Educação Medieval. Alegoria
Abstract

The unity of spirit and matter in medieval anthropology finds its proper place when Thomas Aquinas takes Aristotle's view of reality concerning material realities and the intrinsic union between soul and body. Aquinas surpasses the traditional allegorical way of looking at things. Soul and body work together as a unified entity in every instance of human life. "Anima forma corporis" is very key for liturgy and many aspects of education that otherwise would remain unintelligible because - deep down, as a matter of fact - they are not compatible with exaggerated dualism, which set mind and body in isolation and contrast. Most of medieval educators yet theoretically denying the principle "Anima forma corporis", have based many of their educational practices on it.

Keywords: Soul and body. Thomas Aquinas. Liturgy. Medieval Education. Allegory.

"Anima enim indiget corpore ad consecutionem sui finis: inquantum per corpus perfectionem acquirit et in scientia et in virtute" (CG 3, 144)

\section{Apresentação}

\section{Tomás de Aquino e um novo marco no pensamento medieval}

Examinaremos alguns aspectos de uma contradição que se dá na antropologia e na educação medieval, anteriores a Tomás de Aquino. Certamente essas generalizações ("a antropologia medieval", a "educação medieval") costumam ser perigosas, mas nuances à parte - não são descabidas nesta conferência, se as confrontarmos com a imensa novidade levada a cabo por Tomás em seu pensamento teológico e filosófico. Tomás, na

\footnotetext{
1 Jean Lauand - Prof. Titular Sênior FEUSP e do PPGE da Univ. Metodista de São Paulo. E-mail: jeanlaua@usp.br
} 
esteira do mestre Alberto Magno, incorpora à sua síntese pessoal - entre outros elementos - a atitude de Aristóteles:

Aristóteles se recusa a afastar-se do real concreto, a apartar-se do que está diante dos olhos. E é precisamente essa atitude fundamental que Santo Tomás aceita com toda a veemência. É uma decidida aproximação do concreto, da realidade experiencial do mundo: as coisas concretas que se podem ver, ouvir, saborear, cheirar e tocar são tomadas como algo propriamente real, como realidade por direito próprio e não como mero reflexo ou sombra, não como mero símbolo de outra coisa invisível, do além, não como algo espiritual. Tudo o que é visível e também o ver, o próprio conhecimento sensível e a faculdade desse conhecimento, tudo isso é afirmado e reconhecido como algo válido em si. E isto significa: o mundo corpóreo, a realidade material e - no próprio homem - o corpo, os sentidos e o que eles podem perceber, tudo isso é tomado a sério de um modo inaudito até então (PIEPER, 1973, pp. 255-256).

De fato, nos quadros do pensamento medieval, trata-se de uma aceitação inédita da realidade material e, no homem, da intrínseca união entre espírito e matéria no homem, precisamente o que se expressa pelo conceito aristotélico de alma.

Se no pensamento da Idade Média é com Tomás que se afirma essa intrínseca união entre alma e corpo; o Ocidente, na idade moderna, retoma a tendência a um fragmentarismo, a uma cisão espírito/corpo, desta vez movido por um desmedido afã de clareza no pensamento. Se a tentação medieval de um exagerado dualismo, separando de modo mais ou menos incomunicável e absoluto, por um lado, o espírito (o intelecto, a mente, a "alma"...) e, por outro o corpo e a matéria; a partir de Descartes a dicotomia (res cogitans $\mathrm{x}$ res extensa) tornase dominante.

Dualismo e clareza: na verdade, a última instância do pensamento moderno por detrás da cisão espírito / matéria, está, segundo Heidegger, na pretensão moderna de tornar o ens certum um absoluto:

De bem outra espécie é aquela disposição que levou o pensamento a colocar a questão tradicional do que seja o ente enquanto é, de um modo novo, e a começar assim uma nova época da filosofia. Descartes em suas meditações não pergunta apenas e em primeiro lugar ti tò ón - que é o ente, enquanto é? Descartes pergunta: qual é aquele ente que no sentido do ens certum é o ente verdadeiro? Para Descartes, entretanto, se transformou a essência da certitudo. Pois na Idade Média certitudo não significava certeza, mas a segura delimitação de um ente naquilo que ele é. Aqui certitudo ainda coincide com a significação de essentia. Mas, para Descartes, aquilo que verdadeiramente é se mede de uma outra maneira. Para ele a dúvida se torna aquela dis-posição em que vibra o acordo com o ens certum, o ente que é com toda certeza. A certitudo torna-se aquela fixação do ens qua ens, que resulta da indubitabilidade do cogito (ergo) sum para o ego do homem. Assim o ego se transforma no sub-iectum por excelência, e, desta maneira, a essência do homem penetra pela primeira vez na esfera da subjetividade no sentido da egoidade. Do acordo com esta certitudo recebe o dizer de Descartes a determinação de um clare et distincte percipere. A disposição afetiva da dúvida é o positivo acordo com a certeza. Daí em diante a certeza se torna a medida determinante da verdade. A disposição afetiva da confiança na absoluta certeza do conhecimento a cada momento acessível permanece o páthos e com isso a arkhé da filosofia moderna. (HEIDEGGER, 1973).

Desde Descartes a necessidade de distinguir res cogitans de res extensa, torna-se um imperativo.

Há duas substâncias finitas (res cogitans e res extensa) e uma infinita (Deus). Substância (res) adquiriu um conceito fundamental no século XVII: de natureza simples, absoluta, concreta (realidade intelectual) e completa. Somos portanto uma substância (res) pensante (cogito) e também uma substância (res) que possui corpo, matéria (extensa). Este dualismo cartesiano evidencia que cada indivíduo reconhece a própria existência enquanto sujeito pensante: nossa essência é a razão, o ser humano é racional. O cogito é a consciência de que sou capaz de produzir pensamentos, é um meio pragmático de dar início ao conhecimento. Estamos afirmando, portanto, uma verdade existencial. Há uma coincidência entre meu pensamento e minha existência. (...) O primeiro conceito de Descartes, portanto, denomina-se "dualismo cartesiano", admitindo a existência de duas realidade: alma (res cogitans) e corpo (res extensa). A independência entre alma e corpo conduzirá a uma nova separação: sujeito e objeto (FÉLIX, 2010).

Esse novo páthos era totalmente estranho para um Tomás de Aquino, que afirma - no começo da Suma Teológica - que a dignidade do saber reside no objeto e não na clareza... E recusa também a dicotomia: alma $\mathrm{x}$ corpo. 
Nada mais alheio ao pensamento de Tomás do que uma incomunicação entre espírito e matéria. O que Tomás, sim, afirma é o homem total, a união espírito-corpo, pois a alma, para o Aquinate é forma, ordenada para a intrínseca união com a matéria. Por exemplo, Tomás, indica os remédios para a tristeza, que reside na alma e enfrenta esta questão na Suma Teológica I-II 38 e no artigo 5 chega a recomendar banho e sono como remédios contra a tristeza! Pois, diz o Aquinate, tudo aquilo que reconduz a natureza corporal a seu devido estado, tudo aquilo que causa prazer é remédio contra a tristeza. Tomás destrói assim a objeção "espiritualista":

Objeção 1.: Parece que sono e banho não mitigam a tristeza. Pois a tristeza reside na alma; enquanto banho e sono dizem respeito ao corpo, portanto, não teriam poder de mitigar a tristeza.

Resposta à objeção 1: Sentir a devida disposição do corpo causa prazer e, portanto, mitiga a tristeza.

De resto, para os remédios contra a tristeza, Tomás não fala de Deus nem de Satã, mas sim recomenda: qualquer tipo de prazer, as lágrimas, a solidariedade dos amigos, a contemplação da verdade, banho e sono. E ainda sobre a interação alma-corpo, Tomás afirma em I-II, 37, 4: "A tristeza é, entre todas as paixões da alma, a que mais causa dano ao corpo [...] E como a alma move naturalmente o corpo, uma mudança espiritual na alma é naturalmente causa de mudanças no corpo".

Agir no corpo para atingir a alma; agir na alma para atingir o corpo. Tivesse prevalecido a antropologia de Tomás teríamos estado, desde o século XIII, em muito melhores condições de compreender a natural e necessária condição psicossomática (e somatopsíquica: que o diga meu acupunturista...) de nossa realidade. Tomás é tão "materialista", que nas questões de Quodlibet, tratando do jejum, dirá que o jejum é sem dúvida pecado (absque dubio peccat) (!!) quando debilita a natureza a ponto de impedir as ações devidas: que o pregador pregue, que o professor ensine, que o cantor cante..., que o marido tenha potência sexual para atender sua esposa! Quem assim se abstém de comer ou de dormir, oferece a Deus um holocausto, fruto de um roubo:

Et ideo huiusmodi sunt adhibenda cum quadam mensura rationis: ut scilicet concupiscentia devitetur, et natura non extinguatur; secundum illud Ad Rom., XII, 1: "exhibeatis corpora vestra hostiam viventem; et postea subdit: rationabile obsequium vestrum". Si vero aliquis in tantum virtutem naturae debilitet per ieiunia et vigilias, et alia huiusmodi, quod non sufficiat debita opera exequi; puta praedicator praedicare, doctor docere, cantor cantare, et sic de aliis; absque dubio peccat; sicut etiam peccaret vir qui nimia abstinentia se impotentem redderet ad debitum uxori reddendum. Unde Hieronymus dicit: "De rapina holocaustum offert qui vel ciborum nimia egestate vel somni penuria immoderate corpus affligit; et iterum rationalis hominis dignitatem amittit qui ieiunium caritati, vigilias sensus integritati praefert”. (Quodl. 5, q.9, a.2, c).

Como indicávamos, essa posição de Tomás era excepcional, considerada, em sua época, quase herética:

Na famosa disputa pública que Tomás de Aquino e John Peckham travaram em 1270, diante dos professores e estudantes de Paris, está em discussão a opinião [divergente] de Tomás e apaixonadamente recusada por seu oponente de que no homem há um único princípio vital - a alma espiritual. Isso é o mesmo, expressando-nos de modo menos acadêmico, que afirmar ou combater a afirmação de que o corpo pertence à essência do homem (PIEPER, 1973, p. 148)

A teologia contemporânea recusava a doutrina de uma única alma no homem e afirmava a existência de três (naturalmente a "alma espiritual", independente da matéria é que era considerada a decisiva, em detrimento da "alma vegetativa" e da alma "sensitiva").

\section{Anima forma corporis}

Essa dicotomia gera uma espécie de esquizofrenia no cristianismo: por um lado, propõe-se um cristianismo "espiritual", onde a matéria, o corpo, o sexo e as paixões são maniqueisticamente consideradas "do mal"; mas, por outro - e é o caso da pedagogia 
medieval - aposta-se na matéria (na liturgia, por exemplo) como o grande indutor de atitudes espirituais.

E aí tocamos um dos pontos chave da educação moral, que é sempre, em boa medida, auto-educação. A fórmula vem dada numa aparentemente surpreendente sentença de João Guimarães Rosa: "Tudo se finge primeiro; germina autêntico é depois" (ROSA, 1985, p. 166).

É o caso da educação para as virtudes. Um homem que reconheça um seu defeito moral, digamos a ingratidão, e queira adquirir a virtude correspondente, como deve proceder? Fingindo. Quer dizer, começa-se por assumir as formas externas, verbais da gratidão (que não se sente): "fingir" reconhecer o cárater indevido do favor recebido, "fingir" louvar o benfeitor, "fingir" sentir-se na obrigação de retribuir etc. E, um belo dia, germina autêntico aquilo que se fingia...

"Fingir" é também a proposta de Shakespeare: "Assume a virtue, if you have it not", diz Hamlet (III, 4) $)^{2}$. O costume é monstro que vai comendo o sentido de nossas ações. Mas, o diabo do hábito, torna-se anjo quando se volta para o bem: dando a capa que reveste as ações boas - uma agora, outra depois e outra ainda - e assim ir mudando a natureza e, com prodigioso poder, exorcizar os demônios.

O “fingir" proposto nas Pensées (\#250) de Pascal oferece-nos o enlace com o grande tema da Liturgia. No relacionamento com Deus:

É necessário que o exterior se una ao interior, isto é, pôr-se de joelhos, rezar com os lábios, etc. a fim de que o homem orgulhoso, que não quis se submeter a Deus, seja submetido à criatura. Esperar socorro desse exterior é ser supersticioso; não querer ajuntálo ao interior é ser soberbo ${ }^{3}$.

\section{A liturgia: o corpo induzindo a alma}

É dessa ação (inter-ação) do corpo no espírito que trata o clássico Sinais Sagrados (GUARDINI, 1962), afinal toda a liturgia, como recorda o próprio Guardini, decorre do "anima forma corporis". Nesse pequeno precioso livro, já quase centenário, o mestre alemão vai mostrando o alcance espiritual das realidades materiais: o sino, que - muito mais do que um mero instrumento funcional sinalizador sonoro (como a sirene de uma escola ou o apito de uma fábrica) - despertanos a alma para a grandiosidade do mundo como Criação; os degraus; a porta do templo; a postura corporal na liturgia etc., etc., etc. Fiquemos com um par de exemplos:

\footnotetext{
Os degraus Aqui temos, por exemplo, os degraus. Vezes sem número os subiste já. Mas tomaste consciência do que em ti se passava ao subi-los? Sim, porque de facto acontece qualquer coisa em nós mesmos quando subimos. Somente que é coisa tão subtil e silenciosa que facilmente a podemos deixar passar.

Manifesta-se aqui um profundo mistério. Um daqueles fenómenos que procedem do fundamento do nosso ser humano; enigmático não o podemos resolver pela inteligência, e, no entanto, cada qual compreende-o, porque o nosso ser mais íntimo lhe corresponde.

Quando subimos os degraus, não sobe só o pé, mas também todo o nosso ser. Subimos também espiritual-mente. E se o fazemos conscientemente, pressentimos uma ascensão até aquela altura em que tudo é grande e acabado; o céu onde mora Deus. (...) (pág. 43-44)
}

Ou a porta - a pesada porta - que marca a ruptura entre o profano e o sagrado...

A Porta [A porta do templo] destina-se a cumprir mais do que um simples fim; ela fala. Repara

2. Assume a virtue, if you have it not. That monster, custom, who all sense doth eat. Of habits devil, is angel yet in this, that to the use of actions fair and good He likewise gives a frock or livery, that aptly is put on. Refrain to-night, and that shall lend a kind of easiness to the next abstinence: the next more easy. For use almost can change the stamp of nature. And either.. the devil, or throw him out with wondrous potency.

3. Il faut que l'extérieur soit joint a l'intérieur pour obtenir de Dieu; c'est-à-dire que l'on se mette à genoux, prier des lèvres, etc. afin que l'homme orgueilleux, qui n'a voulu se soumettre à Dieu, soit maintenant soumis à la créature. Attendre de cet extérieur le secours est être superstitieux, ne vouloir pas le joindre à l'intérieur est être superbe. 
como ao transpô-la tens esta sensação: «Agora deixo o que fica lá fora. Entro». Lá fora fica o mundo belo, fervilhante de vida e poder criador. De mistura, existe também muita coisa menos digna: a busca dos seus interesses, por vezes exageradamente. Anda tudo a correr de um lado para o outro, procurando cada qual acomodar-se o melhor que pode. Não queremos dizer que o mundo não seja santo; mas alguma coisa de não santo tem sem dúvida em si. Pela porta entramos num recinto alheio a interesses, silencioso e sagrado: no santuário. Certamente que tudo é obra e dom de Deus. Em toda a parte Ele pode vir ao nosso encontro. (...) E no entanto os homens desde sempre souberam que determinados lugares sao especialmente consagrados, reservados a Deus. A porta está entre o interior e o exterior; entre os interesses e o santuário; entre o que pertence a toda a gente e o que é consagrado a Deus. E diz a quem a tronspõe: «Deixa lá fora o que não pertence cá dentro: pensamentos, desejos, preocupações, vaidades. (pp. 46-47)

\section{Tomás e as faculdades do homem}

Começamos esta conferência, recordando com Pieper que é com Tomás que a realidade material é considerada "como algo propriamente real, como realidade por direito próprio e não como mero reflexo ou sombra, não como mero símbolo de outra coisa invisível (...) o mundo corpóreo, a realidade material e - no próprio homem - o corpo, os sentidos e o que eles podem perceber, tudo isso é tomado a sério de um modo inaudito até então".

E é que a Idade Média anterior à redescoberta de Aristóteles tinha uma visão alegorizante - de dar inveja a nossos carnavalescos... - do mundo criado - fato que, pelo menos, contribuiu para valorizá-lo (não em si, mas por sua relação como sagrado), permitindo o estudo das realidades profanas e das artes liberais para poder ascender ao significado místico das coisas deste mundo. Para essa mentalidade religiosa alegórica (tema de minha conferência ${ }^{4}$ neste evento de 2008), vinda já do cristianismo do mundo antigo - de Alexandria ou de um Agostinho - as coisas são sinais de Deus, pistas para a compreensão da fala de Deus: como enigmas a serem decifradas. Explicando o que é alegoria, diz Agostinho:

Chama-se alegoria a palavra que soa de um modo, mas acaba significando outra coisa diferente. Por exemplo, Cristo é chamado cordeiro (Jo 1,29); acaso é Ele animal? Cristo é chamado leão (Apo 5,5); acaso é Ele fera? É chamado pedra (ICor 10,4); acaso é Ele dureza? É chamado monte (Dan 2,35); acaso é Ele elevação de terra? E, assim, há muitas palavras que soam de um modo, mas são entendidas de outro e a isto se chama alegoria (En. 103, 13)

Assim, deve-se estudar o que são os animais para entender a Cristo: "Vede que vos envio como ovelhas em meio de lobos. Sede, pois, prudentes como serpentes etc.”. O pregador medieval explicará que a serpente passa por entre as pedras para trocar de pele, alegorizando que assim também o cristão deve trocar "sua velha pele", que, por sua vez, alegoriza a vida no pecado etc.

Os famosos versos atribuídos a Alain de Lille ( $P L$ 210:579) expressam essa mentalidade alegorizante:

$\begin{aligned} & \text { Omnis mundi creatura (Do mundo, toda a } \\ & \text { criatura) }\end{aligned}$
Quasi liber et pictura (Como livro e pintura)
Nobis est speculum. (É um espelho para nós)
$\begin{aligned} & \text { Nostrae vitae, nostrae mortis (De nossa vida e } \\ & \text { morte) }\end{aligned}$

Nostrae status, nostrae sortis (De nosso estado e destino)

Fidele signaculum (Um sinal confiável)

Dados da Bíblia para o cristão de hoje totalmente secundários, são, para os antigos e medievais, temas centrais de sua exegese. Os números, por exemplo, como quando da pesca milagrosa - no último capítulo de seu evangelho - , João narra que Pedro trouxe em sua rede 153 peixes grandes (Jo 21, 11). O número 153 , no caso, para o cristão de hoje significa simplesmente uma grande quantidade de peixes. Mas para os medievais, não: esse número - como cada número mencionado na

\footnotetext{
4 “Enigmas, alegoria e religião na educação medieval”. Disponível em: <http://www.hottopos.com/notand18/ enigmas.pdf. Acesso em: 10 out. 2011.
} 
Bíblia - tem um significado místico: é uma mensagem cifrada que deve ser esclarecida pela inteligência cristã. Como era de esperar, essa mentalidade leva a autênticos contorcionismos alegóricos para fazer com que as coisas se encaixem: no caso de nosso 153 , Agostinho, por exemplo, vai jogar com o caráter perfeito dos números 10 (a perfeição da lei) e 7 (perfeição do espírito), que somados dão 17. Ora, a soma dos números de 1 a 17 dá precisamente 153 , o número da multidão dos bem-aventurados (que, da barca de Pedro, que alegoricamente é a Igreja, são levados a Jesus; porque foram apanhados pela rede da atividade evangelizadora etc.).

\begin{abstract}
A explicação do fato de serem 153 peixes é a que costumo fazer-vos [ao menos todos os anos na missa de 6a. f. da Páscoa] e muitos tomam-me a dianteira; no entanto, eu vou repeti-la solenemente $[\ldots]$.

Estes 153 são 17.10 mais 7.10 por quê? 7 por quê? 10 por causa da lei, 7 por causa do Espírito. A forma septenária é por causa da perfeição que se celebra nos dons do Espírito Santo. Descansará - diz o santo profeta Isaías - sobre ele, o Espírito Santo com seus 7 dons (Is 11,23) etc. Já a lei tem 10 mandamentos [...].

Se ao 10 ajuntarmos o 7 temos 17. E este é o número em que está toda a multidão dos bemaventurados. Como se chega, porém, aos 153 ? Como já vos expliquei outras vezes, já muitos me tomam a dianteira. Mas não posso deixar de vos expor cada ano este ponto. Muitos já o esqueceram, alguns nunca o ouviram. Os que já o ouviram e não o esqueceram tenham paciência para que os outros ou reavivem a memória ou recebam o ensino [...] Conta 17, começando por 1 até 17 , de modo que faças a soma de todos os números, e chegarás ao 153. Por que estais à espera que o faça eu? Fazei vós a conta" (Sermão 250, 3)
\end{abstract}

Certamente, essas interpretações medievais são, muitas vezes, forçadas: em alguns casos, o 6, por exemplo, será considerado um número perfeito; em outros, um signo de imperfeição. Pela Aritmética de Boécio, a Idade Média absorve o critério grego: um número é perfeito se a soma de seus divisores próprios perfaz esse número. Assim, perfeito é o $6(6=3+2+$ $1)$, o $28(28=14+7+4+2+1)$, o 496 etc. Esse critério cai como uma luva para explicar a plenitude dos 6 dias da Criação. Mas, no caso do número da besta do Apocalipse (Apo 3, 18), 666, o 6 é a imperfeição (não atinge a plenitude do - segundo outros critérios - perfeito por excelência: o 7).

Rábano Mauro, no séc. IX, chega a escrever um tratado explicando o significado místico de cada número na Bíblia; e os bestiários medievais se encarregarão dos animais - de modo semelhante, mutatis mutandis, aos nossos critérios de interpretação para jogo do bicho: se se sonha com a sogra, vai dar cobra na cabeça; com a homossexual, jacaré; etc. Também para o caso dos animais, como em tudo, cabem interpretações múltiplas e elásticas: o leão é Cristo, mas pode também ser o diabo, que, na epístola de Pedro (IPe 5, 8) "anda rondando como leão que ruge, buscando a quem devorar".

O espaço alegórico diminui consideravelmente em Tomás de Aquino. Por exemplo, no tocante à memória: o jovem Tomás, do Comentário às Sentenças, ainda fala de três potências espirituais: memória, inteligência e vontade. Segue assim, a tradição alegorista do De Trinitate (sobretudo no livro $\mathrm{XV}$ ) de Agostinho, que apresenta a memória como a primeira realidade do espírito, da qual procedem o pensar e o querer: sendo portanto um reflexo de Deus Pai, do qual procedem o Verbo (inteligência) e o Espírito Santo (vontade). Mas já nas obras de maturidade, na Summa e no De Veritate, Tomás rompe com essa visão, situando a memória como faculdade sensível, tal como a têm os "outros animais". Por exemplo, quando na Suma, explica que a memória é parte da Prudência, afirma: "A prudência aplica o conhecimento universal aos casos particulares, dos quais se ocupam os sentidos. Daí que a prudência requer muito da parte sensitiva, na qual se inclui a memória. (III, 49, 1 ad 1)

E Tomás não se preocupa nem um pouco se com isto - o fato de só termos duas, e não três, potências espirituais - perdemos a referência alegórica à Trindade. 
Outro ponto importante é que Tomás centra seu pensamento na Criação, em toda a sua extensão. A Criação é obra de Deus e de sua Inteligência: o mundo foi criado pelo Logos, pelo Verbum e, portanto, conhecer o mundo é conhecer sinais - não meramente alegóricos de Deus. E mais: cada criatura é porque é criada inteligentemente por Deus, participa do ser de Deus. E pode ser conhecida porque recebeu seu ser da Inteligência criadora de Deus. O Deus cristão é Emmanuel, Deus conosco, e pela Encarnação, a eternidade de Deus ingressa na temporalidade e Cristo encabeça, re-capitula (como diz o Catecismo da Igreja Católica) toda a realidade criada.

Tomás de Aquino, leva a sério e às últimas consequências o Prólogo de João. Assim, se o Logos criou todas as coisas, isto significa que as coisas têm - por Criação - uma inteligência fundante estruturando-as por dentro. Então, se eu quiser, digamos, ganhar a vida plantando castanhas, eu devo estudar "castanho-logia", conhecer a racionalidade natural das castanhas (quando devo plantá-las, como adubar etc.) e não procurar iluminações na religião ou nos ministros religiosos. Se eu quero trabalhar com fígado eu devo estudar hepatologia, o logosdo-fígado, e pretender invocar livros sagrados ou autoridades clericais para o tema seria não só descabido, mas até mesmo uma blasfêmia: negar a ação criadora do Logos (e, para Tomás, a compreensão natural dessa realidade com que o homem se encontra é fundamental até para a Teologia).

Isto tem consequências para a teoria do conhecimento (e obviamente para a Pedagogia) de Tomás. Para o Aquinate afirmar que a inteligência é uma potência espiritual é dizer que seu campo de relacionamento é a totalidade do ser: todas as coisas - visíveis e invisíveis são inteligíveis -; "calçam" bem, combinam com a inteligência. Contudo, a relação da inteligência humana com seus objetos não é uniforme. Dentre os diversos entes e modos de ser, há alguns que são mais direta e imediatamente acessíveis à inteligência. É o que Tomás chama de objeto próprio de uma potência: aquela dimensão da realidade que se ajusta, por assim dizer, "sob medida" à potência (ou, melhor dito, é a potência que se ajusta àquela realidade). Não que a potência não incida sobre outros objetos, mas o objeto próprio é sempre a base de qualquer captação: se pela visão captamos, por exemplo, número e movimento (e vemos, digamos, sete pessoas correndo), é porque vemos a cor, objeto próprio da visão. Ora, próprio da inteligência humana - potência de uma forma espiritual acoplada à matéria - é a abstração: seu objeto próprio são as essências abstratas das coisas sensíveis. Próprio da inteligência humana é apreender a idéia abstrata de "cão" por meio da experiência de conhecer pelos sentidos diversos cães: Lulu, Duque e Rex...

Assim, Tomás afirma: "O intelecto humano, que está acoplado ao corpo, tem por objeto próprio a natureza das coisas existentes corporalmente na matéria. E, mediante a natureza das coisas visíveis, ascende a algum conhecimento das invisíveis" (S. Th.. I, 84, 7). E nesta afirmação, como dizíamos, espelha-se a própria estrutura ontológica do homem: mesmo as realidades mais espirituais só são alcançadas, por nós, através do sensível. "Ora prossegue Tomás -, tudo o que nesta vida conhecemos, é conhecido por comparação com as coisas sensíveis naturais". Esta é a razão pela qual o sentido extensivo e metafórico está presente na linguagem de modo muito mais amplo e intenso do que, à primeira vista, poderíamos supor.

Contra todo dualismo que tende a separar exageradamente no homem a alma espiritual e a matéria, Tomás afirma a intrínseca união e mútua ordenação de ambos os princípios. Contra todo "espiritualismo", Tomás conclui: "É evidente que o homem não é só a alma, mas um composto de alma e de corpo" (Summa Theologiae I, 75, 4). E esta união se projeta na operação espiritual que é o conhecimento: "A alma necessita do corpo para conseguir o seu 
fim, na medida em que é pelo corpo que adquire a perfeição no conhecimento e na virtude" (C.G. 3, 144.).

Para Tomás o conhecimento intelectual (abstrato) requer o conhecimento sensível. É sobre os dados do conhecimento sensível que atua o intelecto, em suas duas funções: intelecto agente e paciente.

Essa veemente afirmação do conhecimento natural é também um antídoto contra a pretensão - curiosamente revivida em diversas posturas religiosas de hoje, com perigosas consequências - de que o critério de verdade seja a iluminação divina do líder religioso (padre, pastor, medium, rabino, xeique etc.). Para Tomás, a iluminação de Deus foi-nos dada ao nos conceder o intelecto, com sua natureza própria.
E Tomás propõe a virtude intelectual da prudentia (tema de minha conferência ${ }^{5}$ em outro desse nossos eventos), o exame da realidade pela razão natural, como base de nossas decisões. Sim, todo aquele que crê está legitimado em pedir luzes a Deus para suas decisões (é, segundo a doutrina católica, "conselho", dom do Espírito Santo); o que não se pode é pretender avalizar com a autoridade divina posições meramente temporais. Seja como for, a iluminação sobrenatural deve ser, caso queiramos fazer uso público dela, de tal ordem que torne visíveis para qualquer um a realidade de que se trata. Outra atitude degeneraria em tirania, em teocracia.

\section{Referências Bibliográficas}

FÉLIX, L. “Descartes”. Disponível em: <http://www.esdc.com.br/CSF/artigo_descartes.htm>. Acesso em: 10 nov.2010.

GUARDINI, R. Sinais sagrados Braga: Franciscana, 1962.

HEIDEGGER, Martin Que é isto - a Filosofia? São Paulo: Abril, 1973. Tradução e notas: PIEPER, Josef Filosofía Medieval y Mundo Moderno Madrid: Rialp, 1973.

ROSA, João G. "Sobre a escova e a dúvida" in Tutaméia. Rio de Janeiro: Nova Fronteira. 1985.

STEIN. E. Disponível em: <http://www.scribd.com/doc/3506403/Heiddeger-Que-e-isto-AFilosofia>. Acesso em 10 nov.2010.

5. "Saber Decidir: a Virtude da Prudentia". Disponivel em: <www.hottopos.com/notand11/jean_mauro.htm>. Acesso em 10 out, 2011. 